\title{
Problems of Concluding Business Contracts in Electronic Form
}

\author{
Valentyn S. Shcherbyna
}

Taras Shevchenko National University of Kyiv, Kyiv, Ukraine

Viktoriia V. Rieznikova

Taras Shevchenko National University of Kyiv, Kyiv, Ukraine

Valeria V. Radzyviliuk

Taras Shevchenko National University of Kyiv, Kyiv, Ukraine

\section{Svitlana I. Bevz}

National Technical University of Ukraine "Igor Sikorsky Kyiv Polytechnic Institute", Kyiv, Ukraine

\section{Iryna M. Kravets}

Taras Shevchenko National University of Kyiv, Kyiv, Ukraine

\begin{abstract}
Due to the evolution of modern technologies, first of all the internet, new business opportunities are emerging. Therefore, there is a need to find new forms of concluding contracts. To save time, more and more contracts are concluded in electronic form. In addition, in recent years, there has been a noticeable increase in the use of electronic signatures in business operations. Therewith, an electronic signature of documents is a convenient alternative to handwritten signatures. The purpose of the study is a comprehensive analysis of the problems of concluding business contracts in electronic form and a comparative legal study of the legislation of Austria, Great Britain, Germany, France, and Ukraine regarding the conclusion of such contracts at the international and European levels. The study is based on a systematic approach that helps to comprehensively study the problems of concluding business contracts in electronic form. Furthermore, the study is based on the laws and principles of dialectics, which also contribute to the study of the problems of concluding business contracts in electronic form. The leading methods used in the study included general scientific methods, such as analysis and synthesis, deduction, induction, forecasting, modelling, analogy, as well as a number of special methods of research and cognition, which include comparative legal, historical legal, formal
\end{abstract}

Linguistics and Culture Review (c) 2021.

Corresponding author: Shcherbyna,V.S.; Email: v_shcherbyna6322@tanu.pro

Manuscript submitted: 18 April 2021, Manuscript revised: 27 June 2021, Accepted for publication: 28 July 2021 
legal, and structural-functional methods. The study presents some important issues related to the problems of concluding business contracts in electronic form. In addition, the study provides a comparative analysis of German, French, English, Austrian, and Ukrainian legislation.

Keywords---contract form, electronic digital signature, business contracts, international agreements, electronic document management.

\section{Introduction}

An important factor that affects the validity of a business contract is the form of its conclusion. In accordance with the legislation of Ukraine, for a transaction to take effect, the transaction must take place in the form established by law. Previously, there were only two forms of contract conclusion, namely oral and written. However, the evolution of modern technologies, in particular the Internet, leads to the emergence of new forms of concluding business contracts. According to Paragraph 5 Part 1 Article 3 of the Law of Ukraine "On Electronic Commerce" (2015), an electronic contract is an agreement between two or more parties aimed at establishing, changing, or terminating civil rights and obligations and executed in electronic form. To save time, more and more companies are entering into contracts in electronic form. Another advantage of business contract concluded in electronic form, as noted by M. Schauciunas, is that they have an internally dynamic and flexible nature (Šaučiunas, 2012). Thus, the use of electronic document management in business activities has a positive effect on interaction between business entities (Triasih et al., 2019). Therewith, it is considered that the electronic form of the contract is a kind of written one.

It should be noted that for the first time it is indicated that an electronic document has the same legal force as a paper one in Article 18.1 of the Law of Ukraine "On Payment Systems and Money Transfer in Ukraine" (2001). That is, despite the fact that the legislation of Ukraine establishes a rule regarding the conclusion of business contracts in writing, the adoption of the Laws of Ukraine "On Electronic Commerce", "On Electronic Documents and Electronic Document Management" and "On Electronic Digital Signature" became a prerequisite for the introduction of such a legal instrument as an electronic contract in economic activity (Kuchakovska, 2016). Since then, a number of problems have arisen regarding the conclusion of business contracts in electronic form, which relate in particular to the procedure for conclusion, form, transfer, storage, use as evidence, etc. Notably, an economic contract concluded with the help of modern means of communication constitutes conventional, based on the agreement of the parties, binding legal relations between business entities, the content of which is mutual rights and obligations in the area of economic activity. Its specificity lies in the material carrier on which the content of the contract is recorded. Conclusion of a business contract in electronic form excludes physical contact of the parties (Milash \& Cherkashyn, 2016). 
In addition, the analysis of an electronic digital signature requires special attention. Notably, the use of electronic signatures facilitates e-commerce operations. The convenience of its use is explained by the ability to certify a digital document that can be forwarded by e-mail (Bodnar et al., 2020a; Bodnar et al., 2020b). Therewith, it retains its legality and is mandatory for use as a regular one, made on paper. The main advantages of a digital document are as follows: an electronic signature is unique and cannot be forged; it identifies the person who put it on the document; an electronic digital signature cannot be copied. On the other hand, the use of an electronic digital signature can also lead to uncertainty with regard to the validity of the contract (Sinha \& Singh, 2003; Gupta et al., 2004).

\section{Literature Review}

Today, more and more communications are conducted in electronic form. Sometimes the parties do not even meet physically to conclude business contracts in electronic form (Ueda, 2012; Donaldson \& Dunfee, 2002). In addition, a large amount of information is transmitted electronically. All this raises a number of legal issues, in particular regarding electronic contracts. Some of the most important questions relate to the conditions under which an electronic contract can be valid, whether it must comply with a certain form, whether electronic signatures are acceptable, etc. These issues in the legal doctrine were dealt with by foreign and Ukrainian scientists, among whom the following should be noted: N. Kuchakovska, who studied the legislation of Ukraine on the conclusion of business contracts in written and electronic form, as well as considered the problems of legal regulation of the conclusion of an electronic contract using an electronic signature (Kuchakovska, 2016; Milash \& Cherkashyn, 2016), who were engaged in a comparative legal analysis of the Law of Ukraine "On Electronic Commerce" with foreign analogues; V. Manhora, who analysed various opinions regarding the form of electronic contracts in modern legal science and identified the main problems of legal regulation of economic electronic contracts (Manhora, 2019), etc. As for the form of the agreement, Kuchakovska (2016), notes that the concept of contract form can be defined as a way to reflect the mutual will of the parties to the contract regarding its content on the appropriate information carrier (Morasch, 1995; Wright \& Fergusson, 2009). One should also agree with the position of V. Manhora, who noted that the inclusion of electronic contracts in a separate group of contracts makes provision for amendments to the Civil Code of Ukraine. For this, it is necessary to set out Part 1 of Article 205 of the Civil Code of Ukraine in the following wording: a transaction can be made orally, in writing, or electronically. The parties have the right to choose the form of the transaction, unless otherwise established by law. Separating electronic contracts into a separate form will make it possible to clearly define the essential terms of the contract, reduce the number of cases when the contract is recognised as not concluded or invalid (Manhora, 2019).

On the other hand, to regulate an electronic contract, the same regulatory requirements established in civil and economic legislation apply as for the socalled conventional written paper contracts and in this case the subject matter of the contract remains unchanged; therefore, it remains debatable whether an electronic contract constitutes a separate type of contract (Palanissamy \& 
Kesavamoorthy, 2020; Wang et al., 2019). From a technical standpoint, the conclusion of a business contract using electronic document management is possible both in the case of full and simplified written forms (Hung et al., 2009; Ayaz A., \& Yanartaş, 2020). In compliance with the full written form, when the contract is concluded in the form of a single document signed by the parties and sealed, one electronic document is created, which the parties exchange, sealing it with their electronic signatures (seals). In the case of a simplified written form, the parties exchange various electronic documents, which must necessarily contain electronic signatures (otherwise they will not have legal force) (Palanissamy \& Kesavamoorthy, 2019). Indeed, according to Part 1 Article 181 of the Economic Code of Ukraine, a business contract, as a rule, exists in the form of a single document signed by the parties (Economic Code of Ukraine, 2003). Therewith, it is allowed to conclude business contracts in a simplified form by exchanging letters, fax messages, telegrams, telephone messages, and other means of electronic communication, as well as by confirming acceptance of an order for execution, unless the law establishes special rules for the form and procedure for concluding such type of contract.

An integral part of concluding a business contract in electronic form is the use of electronic signatures. However, the possibility of using an electronic signature greatly simplifies the process of signing business contracts in general. In addition, regarding electronic signatures, Veres (2017), fairly notes that an electronic signature constitutes a set of data in electronic form that performs the functions of identifying the person who signed it and certifying the expression of their will. An electronic digital signature performs another additional function confirmation of data integrity in electronic form. If you use an electronic digital signature with or without an enhanced certificate, an electronic signature with a one-time identifier, or an analogue of a handwritten signature, the written form of the contract is considered to be observed. However, it is necessary to stipulate in the law in which cases the parties to the contract can use them. In case of absence or falsification of an electronic signature, the written form of the transaction is considered to be non-observed.

\section{Materials and methods}

The study of the practice of problems of concluding business contracts in electronic form was implemented by performing the following stages. First of all, the study analysed international standards, joint legislation of the European Union on the conclusion of business contracts in electronic form. Notably, the methodology of this study is a multiple case study of five countries, therefore the study further determines the relevant legislation on the conclusion of business contracts in electronic form in Ukraine and such European countries as France, Germany, Great Britain, and Austria. Based on the above-mentioned study, a comparative analysis of the practice of different states in concluding business contracts in electronic form was conducted. In addition, general conclusions were drawn, as well as prospects and recommendations for concluding business contracts in electronic form were presented.

The study mainly included the analysis of materials from both primary and secondary sources. Primary sources include legislation, decrees, and regulations, 
as well as conventions and agreements (Carraro \& Siniscalco, 1998; Banwell et al., 2020). These primary sources were crucial for determining compliance with national legislation. Furthermore, the study used materials such as textbooks, scientific articles, legal encyclopaedias, seminar materials, and official websites. The study is based on a systematic approach that helps to comprehensively study the problems of concluding business contracts in electronic form. Furthermore, the study is based on the laws and principles of dialectics, which also contribute to the study of the problems of concluding business contracts in electronic form. Thus, the study collected facts, analysed concepts, judgments, and drew conclusions. In the course of this study, previous scientific studies were compared with new ones. Methodologically, this study uses a discourse-analytical approach to the study of the subject matter. The authors examine the context and wording found in documents related to the conclusion of business contracts in electronic form and thus contribute to understanding of how the concept of concluding business contracts in electronic form is created.

The leading methods used in the study included general scientific methods, such as the method of system analysis, analysis and synthesis, deduction, induction, forecasting, abstraction, generalisation, and analogy, as well as a number of special methods of research and cognition, which include comparative legal, historical legal, formal legal, and structural-functional methods. For example, using the system analysis method, a problem situation was formulated; research goals were defined, as well as criteria for achieving goals. In addition, the system analysis method helped to find a solution to this problem. For example, using the deduction method based on other Ukrainian and foreign studies, the author's conclusions were drawn. The induction method also helped to put forward assumptions and suggestions for legal regulation of the conclusion of business contracts in electronic form. Methods of abstraction and generalisation made it possible to identify the main aspects that need to be taken into account upon implementing international standards for concluding business contracts in electronic form in national legislation.

Notably, the leading method in the study was the method of comparative analysis. It helped compare the specific features of the practice of other countries of the world in the field of concluding business contracts in electronic form, as well as to identify how issues related to concluding business contracts in electronic form are regulated in different countries. Information and knowledge from different countries can be used as a basis for the adoption, adaptation, and development of new relevant provisions. In turn, the historical legal method helped consider the objective process of developing international standards in the field of concluding business contracts in electronic form. With the help of the formal legal method, the provisions of law were logically processed using legal techniques, as well as the interpretation of the provisions of law regarding the conclusion of business contracts in electronic form was developed.

\section{Results}

Humanity has entered a new stage in the development of civilization in the $21 \mathrm{st}$ century. The society lives in conditions of constant progress of information technologies and the so-called era of internet distribution, which certainly has a 
considerable impact on doing business, concluding business contracts, etc. Notably, before the advent of the Internet, business contracts were usually concluded in writing or by oral agreement. The UN Convention on contracts for the international sale of goods of 1980 makes provision for the recognition of contracts in the field of the international sale of goods. It does not make provision for e-commerce, but Article 13 stipulates that, for the purposes of the convention, the written form includes telegram and telex. The UN Commission on international trade law has realised that the rise of e-commerce requires it to take steps to recognise that contracts can be concluded over the Internet. In addition, the adoption of uniform rules to remove obstacles to the use of electronic communications in business contracts increases legal certainty and predictability, which facilitates the conduct of international trade. That is why, in 1996, the UNCITRAL Model Law on E-commerce (Draft Uniform Rules..., 2020) was adopted. Notably, the UNCITRAL Model Law on E-commerce was the first treaty to adopt the fundamental principles of non-discrimination, technological neutrality, and functional equivalence, which are widely regarded as fundamental elements of modern e-commerce legislation.

In particular, the principle of non-discrimination ensures that a document will not be denied legal effect, validity, or enforcement just on the grounds that it is in electronic form. The principle of technological neutrality requires the adoption of neutral provisions regarding the technologies used (Reznikova \& Orlova, 2017; Reznikova et al., 2020). In the light of rapid technological progress, neutral provisions are aimed at adapting any future development without further legislative work. The principle of functional equivalence sets out the criteria by which electronic communications can be considered equivalent to paper communications. In particular, it sets out specific requirements that electronic communications must meet in order to perform the same goals and functions as certain concepts in the conventional paper-based system. Thus, the UNCITRAL Model Law on E-commerce requires states to recognize such contracts as legally binding on the parties. The UNCITRAL Model Law on Electronic Signatures of 2001 aims to simplify and facilitate the use of electronic signatures by establishing technical reliability criteria for equivalence between electronic and handwritten signatures. The widespread use of electronic authentication methods as substitutes for handwritten signatures and other conventional authentication procedures indicates the need for a special legal framework to reduce uncertainty regarding the legal consequences that may arise from the use of electronic means. Responding to such needs, the UNCITRAL Model Law on Electronic Signatures relies on the fundamental principle underlying Article 7 of the UNCITRAL Model Law on E-commerce to perform the signature function in an electronic environment, applying a technology-neutral approach that avoids the use of any particular technology or process. In practice, this means that the UNCITRAL Model Law on Electronic Signatures recognizes both digital signatures based on cryptography and electronic signatures using other technologies. The 2005 United Nations Convention on electronic communications was developed based on the UNCITRAL Model Law on E-commerce and the UNCITRAL Model Law on Electronic Signatures (United Nations Convention..., 2005). The convention applies to all electronic communications exchanged by parties whose places of activity are located in different states, when at least one party has a place of activity in a contracting state. In addition, it can also be applied by choice of 
parties. Therewith, contracts concluded for personal, family, or domestic purposes, such as those related to family law and inheritance rights, as well as certain financial transactions, negotiable documents and title documents, are excluded from the scope of application of the convention.

As noted above, the Convention sets out criteria for establishing functional equivalence between electronic means of communication and paper documents, as well as between electronic authentication methods and handwritten signatures. Similarly, the convention defines the time and place of sending and receiving electronic communications. Moreover, the convention establishes the general principle that communications should not be deprived of legal force solely on the grounds that they were made in electronic form. In particular, given the proliferation of automated notification systems, the convention allows for the enforcement of contracts concluded by such systems, including when no individual has verified individual actions performed by them. Moreover, the convention establishes remedies for input errors by individuals entering information into automated notification systems. Finally, the convention allows contracting parties to exclude its application or change its terms to the extent permitted by other legislative provisions. According to the association agreement between Ukraine and the European Union, signed in 2014, national legislation must comply with the main provisions of the legislation of the European Union (Association Agreement..., 2014). Therefore, taking into account Ukraine's European integration aspirations, it is also important to study the legislation of the European Union on the issue of concluding business contracts in electronic form. Notably, in the European Union, the use of electronic signatures is governed by Regulation 910/2014 of the European Parliament and of the Council of 23 July 2014 on electronic identification and trust services for electronic transactions in the Ukrainian market (hereinafter referred to as regulation 910/2014). Regulation 910/2014 applies directly throughout the EU, although each Member State may have additional laws to consider (Regulation (EU) $910 / 2014$ of the European era, 2014).

Regulation 910/2014 differentiates three types of electronic signatures, namely: a simple electronic signature that covers any data in electronic form that is added to other data in electronic form or logically associated with them and used by the signatory for signing. If an electronic signature meets certain requirements, it is called an advanced electronic signature, which means an electronic signature that meets some additional requirements to provide a higher level of reliability. In particular, these requirements are that an electronic signature is associated with a signatory; is capable of identifying the signatory; is created using data to create an electronic signature that the signatory can, with a high level of trust, use under its sole control; is associated with data signed in such a way that any further modification of the data can be detected. The third type of electronic signature, according to regulation 910/2014, is a qualified electronic signature, which constitutes an advanced electronic signature that is created by a qualified device for creating an electronic signature and based on the qualified certificate for electronic signatures. Notably, a Qualified Electronic Signature has the same legal force as a handwritten signature, which means that for all situations where a document is signed with a Qualified Electronic Signature and where the relevant national legislation allows the contract to be executed electronically, a 
Qualified Electronic Signature will have the same presumption of suitability for execution and admissibility as a handwritten signature. Therewith, according to the Law of Ukraine "On Electronic Trust Services" (2017), an electronic document is an original if it contains banking details and a real signature or signature that corresponds to a handwritten one.

Furthermore, according to the legislation of Ukraine, an electronic contract must contain essential conditions, as well as the following information: the procedure (technology) for concluding a contract; the possibility and procedure for making changes to the terms and conditions of the contract; the procedure for creating and imposing electronic signatures by the parties to the agreement; the procedure for exchanging electronic messages and information between the parties in the performance of their obligations; the method and procedure for accepting an offer to conclude (accept) an electronic contract; technical means of identification; references to the terms included in the contract by redirecting (referring) to another electronic document, and the procedure for accessing such a document; the procedure for making changes to a mistakenly sent message about accepting an offer to conclude an electronic contract (conditions for making and receiving paper copies of electronic documents; method of storing and presenting electronic documents, messages, and other information in electronic form and conditions of access to them; ability to choose a language; other information. In this aspect, it should be noted that in Ukraine in 2017, the Law "On Electronic Trust Services" (2017) was adopted, according to which an electronic signature can be of three types, such as those defined by regulation $910 / 2014$, in particular:

- A simple electronic digital signature (low level of trust);

- An improved electronic digital signature (medium level of trust);

- A Qualified Electronic Digital Signature (high level of trust).

It is important that according to Part 4 Article 18 of the Law of Ukraine "On Electronic Trust Services" (2017), only a Qualified Electronic Signature with a high level of trust corresponds to a handwritten one. In addition, in the field of ecommerce, according to Article 12 of the Law of Ukraine "On Electronic Commerce", you can sign an electronic transaction using: an electronic signature (can be represented by clicking on the virtual button "Agree", "Confirm", "Yes", etc.); an electronic signature with a one-time identifier (a combination of letters and numbers that comes to a mobile phone number or e mail, which must then be entered in the appropriate virtual field); an analogue of a handwritten signature (facsimile reproduction of the signature by means of mechanical or other copying, another analogue of a handwritten signature) for by written consent of the parties, which should contain samples of the corresponding analogues of handwritten signatures (Progunova et al., 2019).

\section{Discussion}

The use of electronic communications plays a fundamental role in promoting economic development. However, despite numerous attempts to unify and harmonise this legislation at the international and European levels, it should be noted that the legislation on the conclusion of electronic business contracts differs from country to country. In the course of the study, the authors consider 
the legislation of France, Germany, Great Britain, and Austria. Notably, the French legislation on the form of contracts was amended in 2000. The main purpose of the amendments was to make electronic contracts and signatures equivalent to writing (Mashdurohatun et al., 2020). In particular, article 1366 of the French Civil Code states that a document in electronic form is admissible as evidence if it can be properly identified with the person from whom it originates, and such a document is created under conditions that are likely to guarantee its integrity (French Civil Code, 2016). The main laws of Germany governing the conclusion of contracts in electronic form are: the German Civil Code, which, among other things, states that the written form can be replaced by an electronic form, as well as the German law on trust services, which implements the provisions of regulation 910/2014 on electronic identification and trust services for electronic transactions in the domestic market and promotes the use of electronic trust services (Vertrauensdienstegesetz, 2017).

Thus, in accordance with article 125A of the German Civil Code, the written form of a contract can be replaced by the so-called electronic form, unless otherwise stipulated by law (German Civil Code, 2013). Therewith, according to the German law on trust services, if an electronic form is to replace a written form, it must contain banking details and a Qualified Electronic Signature. If a contract is concluded, the parties must provide their counterparty with an electronic signature. Therewith, a combination of an electronic form and a written form is possible, that is, one party uses an electronic form, and the other signs the contract in writing with a wet ink signature. The use of electronic signatures based on certificates is widespread in Austria. However, in Austria, a person cannot be forced to enter into contracts in electronic form, since the possibility of using a handwritten signature must always be open. The signatures and Trust Services Act of 1999 is the most important source of electronic signature law in Austria (Bundesgesetz über elektronische..., 1999). Based on the signatures and Trust Services Act, the Federal Minister of economy and the Federal Minister of Justice issued a decree on signatures and trust services of 2016, which defines the requirements for:

- The application and issuance of qualified certificates;

- Trust service providers;

- Certificate databases;

- Payment by regulatory authorities (Bundesrecht konsolidiert..., 2016).

Section 886 of the Austrian civil code stipulates that qualified electronic signatures meet the written requirements. That is, qualified electronic signatures are considered the equivalent of a handwritten signature. In English legislation, a contract can be concluded through an offer and an acceptance. Furthermore, the contract must include certain elements subject to legal force, including also the intention to create a legal relationship, certainty of terms and other factors (Zavyalova et al., 2019). In fact, the conclusion of a contract does not always require a signature, although in most official business contracts, the parties decide to sign documents to certify the authenticity of the business contract and agree to its terms and conditions. In this situation, an electronic signature would be legally valid for entering into a contract, if it is applied with the necessary intent and appropriate authority. In addition, for a legal entity, there should be no 
restrictions on the use of electronic signatures in its constituent documents. In accordance with regulation 910/2014 on electronic identification and trust services for electronic transactions in the domestic market, the Electronic Communications Act of 2000 and judicial practice concerning electronic signatures, electronic signatures have legal force when entering into business contracts in electronic form (the Electronic Communications Act, 2000). Regulation 910/2014 on electronic identification and trust services for electronic transactions in the domestic market sets minimum standards for electronic signatures. Together with regulation 910/2014, the Electronic Communications Act 2000 constitutes the main legal document governing the use of electronic signatures in England and Wales. Furthermore, in 2019, the Law Commission (an independent commission set up by Parliament to review the laws of England and Wales) published a report that, in particular, aimed to eliminate legal uncertainty regarding electronically executed documents. According to English law, contracts can be concluded orally, in hard copy or in electronic form, provided that:

- There are key elements of the contract (proposal, acceptance, consideration, certainty of the terms and intention to create a legal relationship);

- In certain cases, appropriate formalities or execution procedures are observed.

Therefore, contracts can actually be concluded using an electronic signature, provided that the parties have not agreed otherwise. Therewith, English legislation has a broad definition of electronic signatures and in itself does not distinguish between different types (Kovova et al., 2018). In addition, English courts accept documents with an electronic signature as prima facie confirmation of the authenticity of the document. If the authenticity of the electronic signature is challenged, the courts will determine on a case-by-case basis whether the electronic signature was legally used.

\section{Conclusion}

The development of technology has led to an unprecedented expansion of electronic document management, an increase in a number of electronic services, as well as an increasingly frequent conclusion of business contracts in electronic form. In addition, the use of electronic communications plays a fundamental role in promoting economic development. The study presents some important issues related to the problems of concluding business contracts in electronic form, as well as the recognition of electronic signatures from the standpoint of international law and European Union legislation. Notably, in the context of Ukraine's European integration aspirations, the legislation of the European Union is a guide for Ukrainian legislation. In addition, the study provides a comparative analysis of German, French, English, Austrian, and Ukrainian legislation. In the late 1980s, a universal organisation, the United Nations Commission on International Trade Law (UNCITRAL), was chosen to develop common e-commerce standards. The work resulted in the UNCITRAL Model Law on E-commerce of 1996, the UNCITRAL Model Law on Electronic Signatures, and the UN Convention on Electronic Communications of 2005. The above-mentioned international treaties have been successful and many countries around the world have signed and ratified these instruments. In addition, the study analysed regulation 
910/2014 on electronic identification and trust services for electronic transactions in the domestic market of 2014, because according to the Association Agreement between Ukraine and the European Union, national Ukrainian legislation must comply with the main provisions of the legislation of the European Union.

However, despite numerous attempts to unify and harmonise the legislation on the conclusion of business contracts in electronic form at the international and European levels, it has its specific features in different countries. Therefore, the study considered the legislation of France, Germany, Great Britain, and Austria on this issue. As for the legislation of Ukraine, there is currently no unified opinion on whether to separate the electronic form of contracts into a separate type, or whether it should remain a subspecies of the written form. In this regard, it is worth noting that to regulate an electronic contract, the same regulatory requirements set out in economic legislation apply as for so-called conventional written paper contracts, and in this case the subject matter of the contract remains unchanged; therefore, there is no need to consider an electronic contract as a separate type of contract.

\section{References}

Ayaz, A., \& Yanartaş, M. (2020). An analysis on the unified theory of acceptance and use of technology theory (UTAUT): Acceptance of electronic document management system (EDMS). Computers in Human Behavior Reports, 2, 100032. https://doi.org/10.1016/j.chbr.2020.100032

Banwell, N., Gesche, A. S., Vilches, O. R., \& Hostettler, S. (2020). Barriers to the implementation of international agreements on the ground: Climate change and resilience building in the Araucania Region of Chile. International Journal of Disaster Risk Reduction, 50, 101703. https://doi.org/10.1016/j.ijdrr.2020.101703

Bodnar, T. V., Reznikova, V. V., Patsuriia, N. B., Radzyviliuk, V. V., \& Kravets, I. M. (2020). Accounting and financial reporting of economic entities: adaptation of Ukrainian legislation to the standards of the European Union. Law and Financial Markets Review, 14(1), 22-28.

Bodnar, T. V., Rieznikova, V. V., \& Kravets, I. M. (2019). Concepts and Signs of Risk in Entrepreneurship. J. Advanced Res. L. \& Econ., 10, 468.

Carraro, C., \& Siniscalco, D. (1998). International institutions and environmental policy: international environmental agreements: incentives and political economy. European economic review, 42(3-5), 561-572. https:/ / doi.org/10.1016/S0014-2921(97)00118-9

Donaldson, T., \& Dunfee, T. W. (2002). Ties that bind in business ethics: Social contracts and why they matter. Journal of Banking \& Finance, 26(9), 18531865. https://doi.org/10.1016/S0378-4266(02)00195-4

Gupta, A., Tung, Y. A., \& Marsden, J. R. (2004). Digital signature: use and modification to achieve success in next generational e-business processes. Information \& Management, 41(5), 561-575. https:/ / doi.org/10.1016/S0378-7206(03)00090-9

Hendriarto, P. (2021). Understanding of the role of digitalization to business model and innovation: economics and business review studies. Linguistics and 
Culture

Review, 5(S1),

$160-173$.

https://doi.org/10.37028/lingcure.v5nS1.1347

Hung, S. Y., Tang, K. Z., Chang, C. M., \& Ke, C. D. (2009). User acceptance of intergovernmental services: An example of electronic document management system. Government Information Quarterly, 26(2), 387-397. https://doi.org/10.1016/j.giq.2008.07.003

Kovova, I., Malyshkin, O., Vicen, V., Shulyarenko, S., Semenova, S., \& Shpyrko, O. (2018). Value added tax: effectiveness and legal regulation in Ukraine and the European Union. Economic annals-XXI, (171), 4-14.

Kuchakovska, N. (2016). Legal regulation of concluding electronic business agreements. Foreign trade: economics, finance, law, 6, 62-74.

Leshchynska, O. A., Firman, V. M., Marych, V. M., Ilchyshyn, Y. V., \& Velykyi, Y. B. (2021). The readiness of a student for constructive social interaction in relation to life safety. Linguistics and Culture Review, 5(S2), 588-598. https://doi.org/10.37028/lingcure.v5nS2.1393

Manhora, W. (2019). Features of legal regulation of electronic business agreements in Ukraine. Information and law, 4, 68-72.

Mashdurohatun, A., Lestari, F., \& Tukinah, U. (2020). Consumer protection of the listing of standard clause in e-commerce transactions based on the value of Pancasila justice. International Journal of Advanced Science and Technology, 29(6), 1520-1531.

Milash, V., \& Cherkashyn, S. (2016). Some aspects of concluding an electronic contract. Law and society, 3, 87-91.

Morasch, K. (1995). Moral hazard and optimal contract form for R\&D cooperation. Journal of Economic Behavior \& Organization, 28(1), 63-78. https://doi.org/10.1016/0167-2681(95)00020-5

Palanissamy, A. \& Kesavamoorthy, R. (2020). Web contracting and standardization of standard form contracts in the electronic age. International Journal of Scientific and Technology Research, 9(3), 1170-1173.

Palanissamy, A., \& Kesavamoorthy, R. (2019). Digitalization of transactions and consumer protection in wrap contracting. International Journal of Engineering and Advanced Technology, 8(6), 3993-3996.

Progunova, L., Voronova, T., Bogatyreva, S., \& Kostyukova, O. (2019). Innovative aspects of preferential rules of goods origin in the economy of global chains: applicability for the Eurasian Economic Union (EAEU). In IOP Conference Series: Materials Science and Engineering (Vol. 497, No. 1, p. 012048). IOP Publishing.

Reznikova, V.V., Kravets, I.M., Sviatotskyi, O.D. (2020). Risk management in business: The problems of regulatory framework. Asia Life Sciences, 22(2), 625638.

Reznikova, V.V., Orlova, O. S. (2017). E-commerce: international experience and problems of legal regulation in Ukraine. Eurasian Academic Research Journal, 2(8), 41-52.

Sauciunas, M. (2012). Automated eContract Negotiation in Web Service Environment: Electronic Contract Management Aspects. In DB\&Local Proceedings (pp. 241-247).

Sinha, A., \& Singh, K. (2003). A technique for image encryption using digital signature. Optics communications, 218(4-6), https://doi.org/10.1016/S0030-4018(03)01261-6

229-234. 
Triasih, D., Heryanti, B. R. \& Pujiastuti, E. (2019). Legal protection for consumers in buying agreements online. International Journal of Innovation, Creativity and Change, 10(4), 127-142.

Ueda, K. (2012). Banking globalization and international business cycles: Crossborder chained credit contracts and financial accelerators. Journal of international Economics, 86(1), 1-16. https://doi.org/10.1016/j.jinteco.2011.08.012

Veres I. (2017). Legal regulation of electronic signatures. Enterprise, economy and law, 3, 11-15.

Wang, J., Sun, G., Gu, Y., \& Liu, K. (2019, October). Distributed Electronic Data Storage and Proof System Based on Blockchain. In CCF China Blockchain Conference (pp. 48-67). Springer, Singapore.

Wright, J. N., \& Fergusson, W. (2009). Benefits of the NEC ECC form of contract: A New Zealand case study. International Journal of Project Management, 27(3), 243-249. https://doi.org/10.1016/j.ijproman.2008.03.005

Zavyalova, E. B., Shumskaia, E. I., \& Kuzmin, M. D. (2019, December). Smart Contracts in the Russian Transaction Regulation. In Institute of Scientific Communications Conference (pp. 205-212). Springer, Cham. 